\title{
Life Changing Prescription: The Dangers of Vicodin and How It Can Become Addicting to College Students
}

\author{
LaVelle Hendricks ${ }^{1}$ \& Gabriela Reyes ${ }^{1}$ \\ ${ }^{1}$ Department of Psychology, Counseling, and Special Education, College of Education and Human Services, Texas \\ A\&M University-Commerce, Commerce, TX, USA
}

Correspondence: LaVelle Hendricks, EdD, Associate Professor of Counseling, Department of Psychology, Counseling, and Special Education, College of Education and Human Services, Texas A\&M University-Commerce, Commerce, TX, USA.

Received: October 23, 2015

Accepted: November 12, $2015 \quad$ Online Published: November 2, 2016

doi:10.5430/irhe.v2n1p1

URL: http://dx.doi.org/10.5430/irhe.v2n1p1

\begin{abstract}
The use of Vicodin has become very popular amongst college students. Yet, the students who seem to consume this drug have little knowledge about what the drug is capable of doing. Many times, college students seek the use of prescribed and non-prescribed drugs in order to find the relief they are looking for from everyday life. Some students may think of pain relievers as an acceptable method, but they soon fail to realize that their life has changed for the worse because of the use of this drug. They will often be seeking intensive therapy in order to battle their addiction. It is important that students are aware of the valuable resources available to them on campus and use them to their advantage.
\end{abstract}

Keywords: vicodin, college students, narcotics, addiction

\section{Introduction}

We live in a world that seems to be highly dependent on various types of medicines. Whether they are prescribed or not, these medications can alter us mentally, emotionally, and physically. A very commonly prescribed drug, known as Vicodin, can cause such a change. What is Vicodin exactly made of? Vicodin is a combination of acetaminophen and hydrocodone. Hydrocodone is part of a group of drugs called opioid pain relievers or narcotics (Drugs, 2013). Acetaminophen (Tylenol) is known as a less effective pain reliever that helps increase the effects of hydrocodone (Drugs, 2013).

The main purpose of this article is to provide as much information as possible about the dangers of Vicodin and how it is easily abused by college students. Vicodin is among one of the most commonly abused pain killers in the U.S. and in other countries (Vicodin Abuse, 2011). Vicodin is frequently abused due to the fact that it is widely prescribed for pain relief for various common conditions such as toothaches, backaches, osteoarthritis pains, post-surgical and other types of pains (Vicodin Abuse, 2011). The fact that Vicodin has its own hydrocodone generic form makes it more affordable and easier to abuse. No one deliberately decides to become a Vicodin addict, but unfortunately many people who are prescribed this medication following surgery, an injury or chronic pain often feel that they are not getting the adequate amount of pain relief they expected from the medication. Therefore, individuals may start to use the medication more often than recommended, and this type of behavior often leads to Vicodin addiction. Peer pressure is another motive for college students to abuse Vicodin, as well as the stresses and responsibility of school. To some college students, Vicodin is a way to relieve and escape their stress, but unfortunately this drug can have damaging effects on the student's academic, social and physical well-being. If the student is facing trouble with addiction to Vicodin, it is critically important for them to get their life back on track. The damaging effects of Vicodin can ruin the student's dreams and goals and even put an end to them as well.

\section{College Students Who Become Victims of Vicodin}

Among some of the individuals who may fall victims to Vicodin abuse are college athletes who can find themselves battling addiction after taking Vicodin for an injury (Vicodin Abuse Help for College Students, 2010). College athletes can become addicted to Vicodin because of fear that the pain will return or the attachment to the way Vicodin makes them feel. The abuse of prescription drugs among American college students is often linked to 
depression and suicidal thoughts. In a previous study, researchers were able to analyze more than 26,000 college students at 40 campuses. In this study, a survey was conducted in which the students were asked if they had used prescription drugs such as painkillers, stimulants, sedatives and antidepressants for non-medical purposes, and they were also asked about their mental health symptoms over the past year ("More Mental Health Woes," 2012). The results to the questions showed that about 13 percent of college students reported nonmedical use of prescription drugs (More Mental Health Woes," 2012).

Another study was conducted among National Collegiate Athletic Association (NCAA) male athletes who were known to use banned performance enhancing substances. In this study, 11,556 male undergraduate college student athletes were recruited. Ninety-eight percent of the participants reported being between the ages of 18 and 23 years of age; $75 \%$ of participants reported their race as White; $15 \%$ as Black/African American; 5\% as Hispanic or Latino; $2 \%$ as American Indian/ Alaskan Native; $2 \%$ as Asian; and $1 \%$ as Native Hawaiian or Pacific Islander (Buckman, Farris, \& Yusko, 2013) In this study, the use of pain killers was measured by asking the question "Within the last 12 months, have you taken any of these pain management medications with or without prescription?" The response specifically referred Vicodin, Oxycontin, and Percocet, all of which contain narcotics (Beckman, Farris, \& Yusko, 2013). Participants were also asked to mark all that apply: (1) I have not taken pain management medication with or without a prescription; (2) I have taken Vicodin, Oxycontin or Percocet with a prescription; (3) I have taken Vicodin, Oxycontin or Percocet without a prescription; and (4) I have taken other pain management medication (Beckman, Farris, \& Yusko, 2013). The students who chose options (2) or (3) were identified as past year users of narcotic-based pain management medications (Beckman, Farris, \& Yusko, 2013). The article also demonstrated that college athletes struggle with far more stress than a typical college student would. Thus, they are often most likely to have higher risks for problematic substance use behaviors, in terms of alcohol and drugs, which are prevalent in college environments and performance enhancing substances which continue to be a major concern at all levels of athletics (Beckman, Farris, \& Yusko).

The most valuable aspect of this study was that self-reported drug use may vary depending on whether specific drug versus general drug categories are referenced in the survey (Beckman, Farris, \& Yusko). A given example in this article showed that the number of male student athletes who reported past year use of "narcotics" was substantially lower $(\mathrm{n}=332)$ than the number of student athletes who responded to a "pain management medications" by specifically stating the use of Vicodin, Oxycontin, and Percocet $(n=1868)$ (Beckman, Farris, \& Yusko). From this data, it may be assumed that college athletes do not have the necessary knowledge of a drug's physiological action, side effects and abuse profiles (Beckman, Farris, \& Yusko). It also helps researchers to be aware of how important it is to ask specific questions in order to get better responses. Alternatively, it pointed out that athletes may be likely to underreport their habits when asked about broader drug categories rather than specific drugs due to fear of possible consequences from admitting use (Beckman, Farris, \& Yusko). The study focuses more on male NCAA athletes only, so studies about female athletes may be different. This article also raises awareness in the fact that further contributions must be made in order to help college athletes become more knowledgeable of specific drugs. If college athletes do not receive better drug education and stronger prevention messages, then enhancing substance use is likely to remain high (Beckman, Farris, \& Yusko).

\section{The Reality of College Life}

We know that college students face hectic lives each and every day. Students are seeking a variety of drugs, like Vicodin, just to cope with the extreme pressure and anxiety of achieving good grades, attending class, holding down a job or internship, having a social life and finding time to sleep (Acquah, Bonnay, \&Massanari, 2012). Many students have made a choice to use non-prescribed prescription drugs in hopes of improving their academic performance (Acquah, Bonnay, \& Massanari, 2012). One 21-year-old biomedical student states "I need more hours in the day, and this helps me accomplish everything I need to get done efficiently." (Acquah, Bonnay, \& Massanari, 2012) This 21-year-old student does not see taking non-prescribed prescription drugs as a serious issue. This situation is not only occurring to this 21 -year-old student, but it is happening nationwide.

\section{Signs, Symptoms, and Treatment}

With the rise of prescribed medications such as Vicodin to alleviate pain, there has been a big concern from those who oppose the use of such a drug. When a person takes Vicodin under legitimate reasons, such as injury, surgery, and chronic pain, the body will slowly adapt to the effects of Vicodin. As the individual's body becomes used to the effects of Vicodin, the patient will then have no other choice but to take a higher dose than usual in order to find the relief they need for their pain (Vicodin Abuse, 2011). Having to use a larger does than needed is usually one of the first signs of Vicodin dependence and addiction. Other various signs of Vicodin abuse include getting relief from 
pain if only unusually higher doses of Vicodin are taken, involuntarily taking medication because of factors beyond your control and withdrawal symptoms when you do not take the medication (Vicodin Abuse, 2011). There are various symptoms of Vicodin abuse which include insomnia, involuntary leg movement, watery eyes, cold flashes and bone pain. (Vicodin Abuse, 2011) It is very important that college students take into consideration the various complications of Vicodin. Students who have become victims of Vicodin must not lose hope because there are various types of ways to treat Vicodin addiction. One of the first steps that should be taken would be to go through a detoxification process. This process will help the individual remove the drug from their system (Vicodin Abuse, 2011). Another step that can help treat this addiction is through intensive therapy. Through long periods of therapy, the student will be able to explore the issues that led to the dependency and will discover alternative ways to handle those different issues (Vicodin Abuse, 2011).

\section{Conclusion}

College students need to be aware of the different effects that Vicodin can cause them. If a student is considering taking Vicodin, they must first make sure that they are well informed of all of the possible risks and dangers that can occur. For students who have become victims of Vicodin, it is important for them to keep in mind that there are always solutions to claim their life back. Prescription drugs might seem like the solution to many of life's problems, but it is certainly harder to control once addicted. There are a lot of valuable resources available on campus for students to stay safe and well informed. Students should consider visiting their campus library or counseling center to find all of the help and information they need.

\section{References}

Acquah, D., Bonnay, S., \& Massanari, J. (2012, January 31). Up all night: some college students abusing prescription drugs. $\quad$ Retrieved from http://azdailysun.com/news/local/state-and-regional/up-all-night-some-college-students-abusing-prescription-dr ugs/article_8e2a5d89-27bb-5eb3-b00c-19de2efce8fe.html

Beckman, J.F., Farris, S.G., \& Yusko, D.A. (2013, July 1). A national study of substance use behaviors among NCAA male athletes who use banned performance enhancing substances. Drug and Alcohol Dependence, 131, 1-2, p50-p55, 6p. Retrieved from http://proxy.tamucommerce.edu:8049/science/article/pii/S037687161300152X

Drug Information Online. (2012, June 19). More mental health woes in college kids who abuse prescription drugs. Retrived from http://www.drugs.com/news/more-mental-health-woes-college-kids-abuse-38839.html

Drug Information Online. (2013). Retrieved from http://www.drugs.com/vicodin.html; http://vicodinabuse.org/

StopOxy. (2013). Prescription drugs on campus- oxy and Adderall are being abused. Retrieved from http://www.stopoxy.com/prescription-drugs-campus-oxy-adderall-vicodin-oxycontin

Tejeda, V. (2012, June 15). Stressed students abuse painkillers to cope. The Fix. Retrieved from http://www.thefix.com/content/stress-students-abuse-painkillers-90261

Vicodin Abuse and Withdrawal Symptoms. (2011, July 27). Retrieved from http://vicodinabuse.org/

Vicodin Abuse Help for College Students. (2010). Retrieved from http://www.vicodin-rehab-guide.com/vicodin-rehab/vicodin-abuse-help-for-college-students/ 